\title{
Novel approach to the interpretation of long-term "deterioration" in ejection fraction in individual patients with coronary artery disease
}

\author{
Richard Lim, Lorraine Dyke, Janice Thomas, Duncan S Dymond
}

\begin{abstract}
Objective-The long-term predictability of left ventricular ejection fraction (LVEF) measurements was evaluated with particular emphasis on the assessment of deterioration in individual patients whose coronary artery disease was initially treated medically.

Design-Prospective pilot study.

Setting-Regional cardiac centre.

Patients-60 minimally symptomatic patients with coronary artery disease who, after arteriography, were initially treated medically.
\end{abstract}

Intervention-Measurement of LVEF by first pass exercise radionuclide ventriculography at baseline and six months later without interruption of usual antiischaemic medication. Baseline and six-month studies were analysed independently of each other.

Main outcome measure-Based on 51 patients who remained event free, $95 \%$ prediction intervals were derived for prognostic LVEF indices to suggest the minimum change from baseline that might be considered clinically important in the individual patient, alerting clinicians to the need for closer review.

Results-At six-month ventriculography, 22 patients showed apparent deterioration in exercise LVEF or the change in LVEF with exercise (ALVEF). Only two patients had six-month values below the lower limit of $95 \%$ prediction intervals, compared with 15 when $95 \%$ group confidence intervals $(z=3.33, p<0.001)$ were used. When $\triangle L V E F=0$ at baseline, the lower limit of $95 \%$ prediction intervals allowed for an exercise induced fall at six months of $\leqslant 13 \%$. For a baseline exercise LVEF of $50 \%$ (just normal), the lower limit of $95 \%$ prediction intervals was $38 \%$-that is, the exercise LVEF could be measured as low as $38 \% \geqslant$ six months later without necessarily indicating or missing true deterioration.

Conclusion-In the follow up of minimally symptomatic patients with coronary artery disease, serial long-term changes, in particular "deterioration," in prognostic LVEF indices may be interpreted more meaningfully with reference to $95 \%$ prediction intervals.

(Br Heart $\mathcal{F} 1993 ; 70: 226-232)$

In the prognostic evaluation of coronary artery disease by radionuclide ventriculo- graphy, left ventricular ejection fraction (LVEF) at peak exercise is probably the most important predictor of cardiovascular mortality, ${ }^{12}$ whereas the change in LVEF from rest to exercise ( $\triangle \mathrm{LVEF}$ ) may better describe the risk of ischaemic morbidity. ${ }^{134}$ In patients initially treated medically, deterioration in these prognostic indices despite anti-ischaemic medication may predict failure of that medical treatment. ${ }^{5}$ As potential candidates for subsequent revascularisation, such patients may benefit from follow up that includes serial objective assessment to detect deterioration in the individual patient. We have therefore examined prospectively the longterm reproducibility of, and prediction intervals for, LVEF measurement in individual patients by radionuclide ventriculography performed without interruption of medication.

\section{Patients and methods \\ PATIENTS}

After coronary arteriography performed primarily for the investigation of known or suspected coronary heart disease, 60 patients were recommended to continue with medical treatment on the basis of minimal angina and arteriographic disease that did not need early revascularisation. Nonetheless, all had disease that could revascularised, visually defined as $\geqslant 50 \%$ luminal diameter stenosis in at least one major epicardial artery. Patients were excluded if they had previously been revascularised, or were being investigated for arrhythmias, or had left main stem disease, overt heart failure, atrial fibrillation, or valve disease. Informed consent was obtained in all cases.

ANTI-ISCHAEMIC MEDICATIONS

All patients were already stabilised on regular conventional anti-ischaemic medication. Such medications were optimised so that no patient had angina worse than Canadian Cardiovascular Society class $I$ in the four weeks before the baseline exercise radionuclide ventriculogram. Medications were maintained as normal provided there was no change in clinical state during the study.

EXERCISE RADIONUCLIDE VENTRICULOGRAPHY Between two and three months after coronary arteriography, each patient underwent first pass radionuclide ventriculography with the Scinticor multicrystal gamma camera system (Scinticor Inc, Wisconsin, USA). At baseline and six months later, each complete test com- 
prised a resting then an exercise ventriculogram. The total amount of radioactivity given (effective dose $8 \mathrm{mSv}$ ) was judged to be safe by the local radiation protection adviser. Patients were exercised to the same duration and workload during repeat tests at six months.

Tests were scheduled between 1015 and 1230 at least three hours after a meal. The right median basilic vein was cannulated with an 18 French gauge plastic cannula. The patient was then connected to an electrocardiograph monitor and seated on a Fitron cycle ergometer with the chest against the camera detector in the anterior upright projection.

After several minutes to allow patient familiarisation, a dose of $40 \mathrm{MBq}$ of technetium ( ${ }^{99 \mathrm{~m}} \mathrm{Tc}$ ) pertechnetate was injected to avoid malpositioning, ${ }^{6}$ then the resting ventriculogram was taken. This was done by giving a rapid $12 \mathrm{ml}$ saline flush injection of a $0.5 \mathrm{ml}(300 \mathrm{MBq})$ bolus of ${ }^{99 \mathrm{~m} T c}$ pertechnetate to maximise bolus integrity. ${ }^{7}$ Imaging occurred simultaneously and continued for 15-30 seconds at $40 \mathrm{~ms}$ framing intervals. On line data acquisition on to hard disc was followed by storage onto magnetic tape for later processing and analysis.

Graded exercise was then started from zero to a workload of $400 \mathrm{~kg} \mathrm{~m} / \mathrm{min}$ at which it was maintained for the first two minutes. Thereafter, workload was increased by $200 \mathrm{~kg}$ $\mathrm{m} / \mathrm{min}$ every two minutes until a symptom limited peak was reached. At this point, with the patient maintaining peak exercise for 20-40 seconds, several background frames were collected before a second rapid $12 \mathrm{ml}$ saline flush injection of a $0.5 \mathrm{ml}(450 \mathrm{MBq})$ bolus of ${ }^{99 \mathrm{~m}} \mathrm{Tc}$ pertechnetate. Frames were collected at $20 \mathrm{~ms}$ intervals, and on redistribution of radioactive tracer, exercise was ended. Again, data were transferred and stored on magnetic tape for computer processing and analysis with Baird software (Baird, Massachussetts, USA).

\section{DATA ANALYSIS}

In this investigation of patients with documented coronary artery disease, the computer calculated quantitative radionuclide variables of principal prognostic interest were LVEF at rest and at peak exercise, and $\triangle \mathrm{LVEF}$.

All studies were analysed by consensus between two experienced observers. The six month studies were analysed by these observers blinded to the results of the baseline analysis. Consensus on technical quality was required for each study. If study quality was suboptimal, the choice of background frame was re-examined to see if both consensus and improvement in computer generated analysis were possible; if not, the study was rejected.

\section{STATISTICS}

Analyses were carried out with the Minitab version 7·1 (Minitab Inc, Philadelphia, USA). Results were considered statistically significant at the $<0.05$ level (two tailed).
Linear regression analysis by the method of least squares was used to fit a straight line through the origin of six-month measurements as a function of baseline LVEF values. The rationale for forcing the regression line through the origin was to test the hypothesis that the slope for the regression of six-month values on baseline measurements was equal to unity. The residual SD was a measure of the goodness of fit of the regression line to the observed data.

For any given baseline LVEF, 95\% confidence intervals (95\% CIs) for the regression line include with $95 \%$ probability the true mean six-month value in the population. To allow for random variation and define whether a change found at six months is likely to be real in the individual patient, $95 \%$ prediction intervals were also derived. ${ }^{8}$ For a given baseline value, there was a $95 \%$ probability that an individual patient's measurement six months later would lie within the interval. A measurement at six months that exceeds the lower limit of $95 \%$ prediction intervals would either occur by chance ( 1 in 20 ) or indicate with $95 \%$ certainty a true change-that is, a deterioration from baseline. To compare the proportions with "deterioration" as defined by the $95 \%$ prediction intervals or $95 \% \mathrm{CIs}$, McNemar's test with continuity correction was used.

\section{Results}

One patient had a technically poor quality baseline study. Four required adjustment in their medication. Interim events occurred in four others (non-fatal myocardial infarction in two, unstable angina in one, and coronary angioplasty for recurrent angina in one). Therefore these nine patients did not undergo. repeat tests at six months and were excluded from further analysis.

\section{PATIENT CHARACTERISTICS}

Paired data were available for analysis from the final study group of 51 subjects (mean age 56 (range $32-71$ years; 42 men) without disqualifying events (death, myocardial infarction, unstable angina requiring hospital admission) or new pathological $Q$ waves on their 12 lead electrocardiogram at six months. Forty patients had had remote ( $\geqslant 6$ months) myocardial infarction. Significant luminal stenosis was present in one coronary artery in 23 , in two arteries in 18 , and in three arteries in 10 patients. Angina was well controlled by a single agent in 29 patients $(\beta$ blocker in 15, calcium blocker in 10 , and long acting nitrate in four). Five patients were on triple treatment.

Table 1 summarises the test results at baseline and six months. Figure 1 shows the linear regression plots for resting LVEF, exercise LVEF, and $\triangle \mathrm{LVEF}$. Figure 2 shows the plots of the difference between six-month and baseline measurements against the average of their sum'; the respective Pearson correlation coefficients were not significantly different from 0 -that is, the difference between six- 
Table 1 Variables from first pass radionuclide ventriculography in 51 patients

\begin{tabular}{lcccc}
\hline & Baseline & 6 month & $p$ value & $95 \%$ I \\
\hline Resting LVEF (\%) & $50(22$ to $71 ; 12)$ & $50(22$ to $77 ; 12)$ & 0.62 & -1 to +1 \\
Exercise LVEF (\%) & $47(23$ to $83 ; 12)$ & $49(24$ to $72 ; 12)$ & 0.12 & 0 to +3 \\
ALVEF (\%) & $-2(-27$ to $+24 ; 10)$ & $-1(-28$ to $+17 ; 11)$ & 0.27 & -1 to +3 \\
Maximum workload (kg m/min) & $743(400$ to $1200 ; 164)$ & $745(400$ to $1200 ; 171)$ & 0.80 & -13 to +17 \\
Duration of exercise (min) & $5.4(3$ to $9 ; 1)$ & $5.3(3$ to $9 ; 1)$ & 0.36 & -0.3 to +0.1 \\
Resting heart rate (beats/min) & $63(42$ to $111 ; 15)$ & $65(38$ to $106 ; 13)$ & 0.33 & -2 to +5 \\
Exercise heart rate (beats/min) & $131(85$ to $181 ; 21)$ & $133(71$ to $168 ; 20)$ & 0.36 & -3 to +8 \\
$\Delta$ Heart rate (beats/min) & $68(11$ to $108 ; 19)$ & $69(21$ to $96 ; 18)$ & 0.69 & -3 to +5 \\
\hline
\end{tabular}

Values are expressed as mean (range; SD); $95 \% \mathrm{CI}, 95 \%$ confidence interval for mean difference between baseline and six month values.

month and baseline measurements was independent of baseline magnitude for LVEF at rest and exercise, and $\triangle \mathrm{LVEF}$.

RESTING LVEF

There was no significant variability in resting LVEF (mean (SD) $0 \%(4 \%), 95 \% \mathrm{CI}-1$ to +1 ) for the entire group (table 1). In the 29 patients with normal baseline values $(\geqslant 50 \%)$, there was also no between-test

Figure 1 Scatterplots for resting $L V E F$ (top), exercise LVEF (middle), and $\triangle L V E F$ (bottom).

Points may represent multiple observations. The regression line is the thick line, $95 \%$ CIs the thin lines, and $95 \%$ prediction intervals the dashed lines.

From any baseline measurement on the horizontal axis, a line is drawn perpendicularly to meet the lower limit of $95 \%$ prediction intervals, the value of which is read off the vertical axis. This

value represents the six month measurement below which there is a $95 \%$ probability of true deterioration.
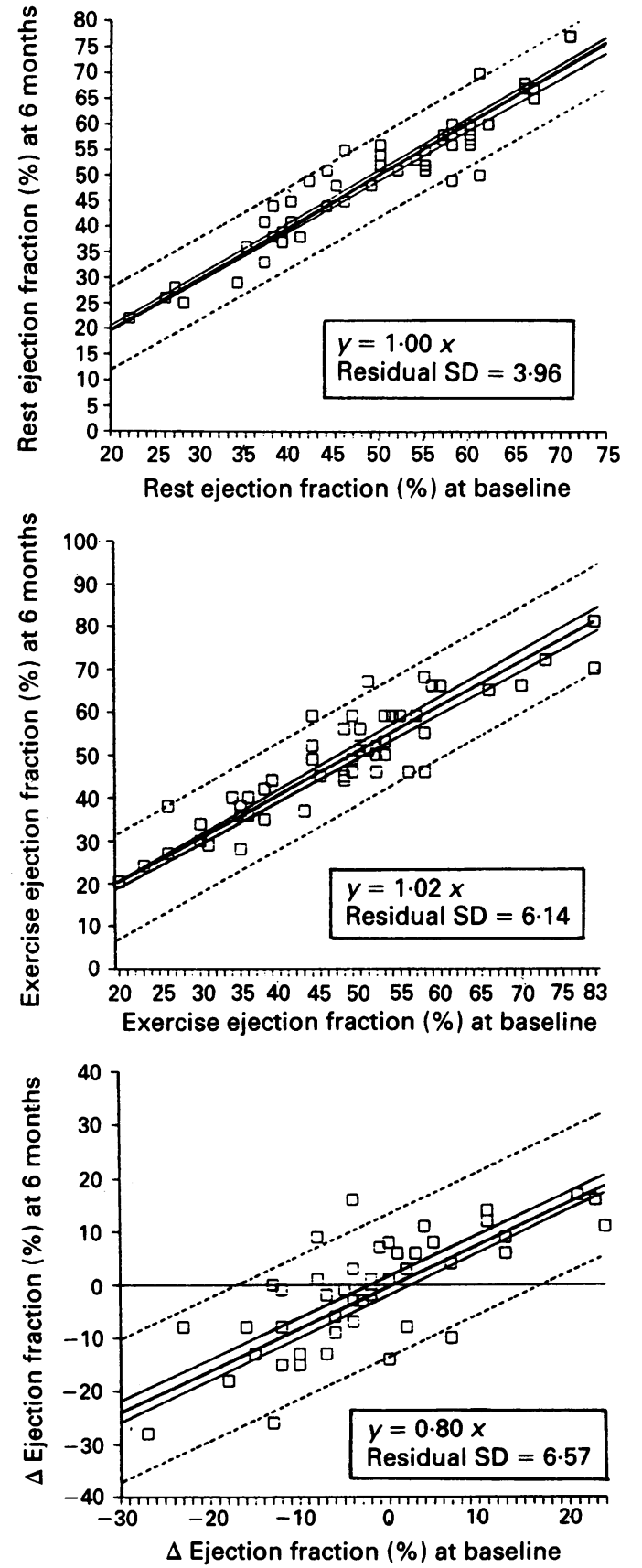

difference (mean $0 \%(4 \%) ; 95 \% \mathrm{CI}-2$ to +1 ). The proportion of patients with $<10 \%$ absolute difference between baseline and sixmonth measurements was 50 of 51 (98\%; fig 3).

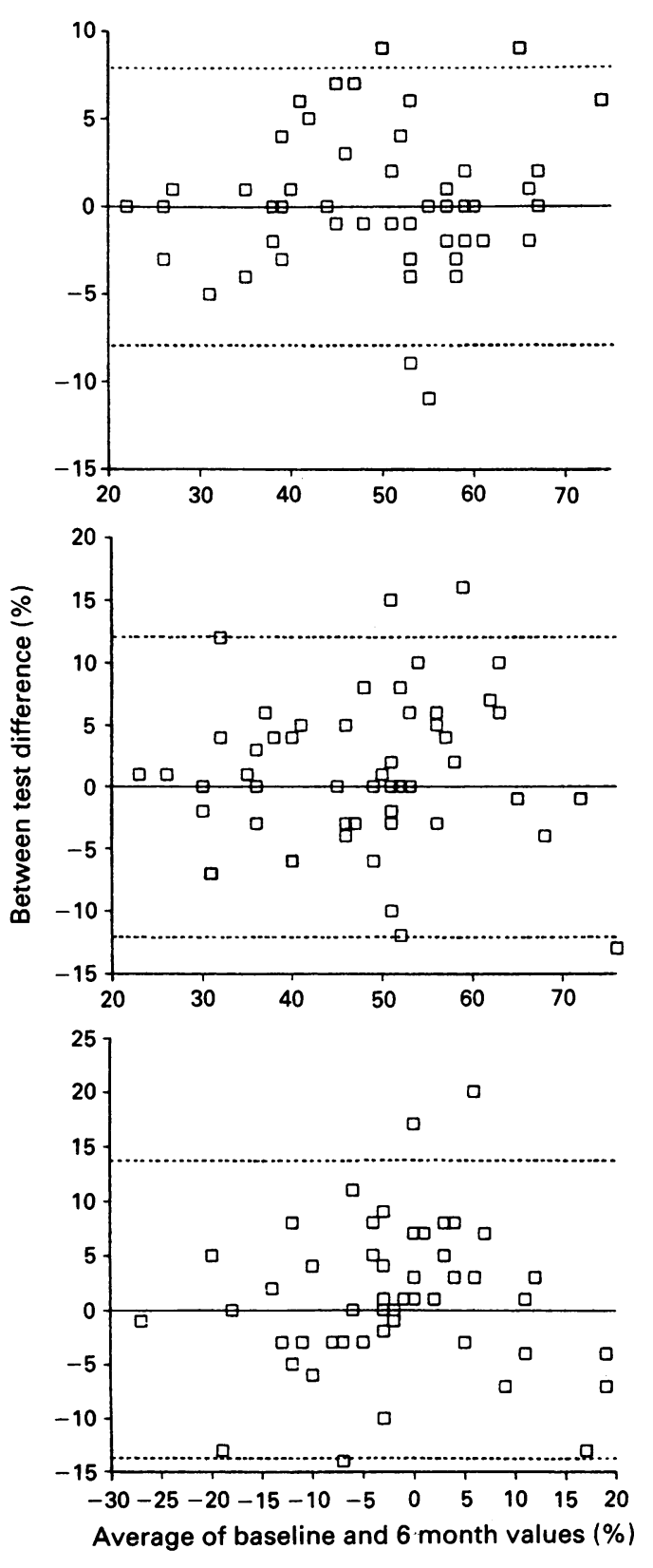

Figure 2 Plots of the difference between six month and baseline values against the average of their sum. Dashed lines denote (2 SDs). Points may represent multiple observations. The correlation coefficient for resting LVEF (top) was 0.074 (95\% CI -0.206 to 0.343), exercise LVEF (middle) -0.014 (95\% CI -0.288 to 0.263 ), and $\triangle L V E F$ (bottom) 0.045 (95\% CI -0.233 to $0 \cdot 317)$. 
Figure 3 Frequency distribution of absolute differences between baseline and six month values for resting LVEF (top), exercise LVEF (middle), and $\triangle L V E F$ (bottom).
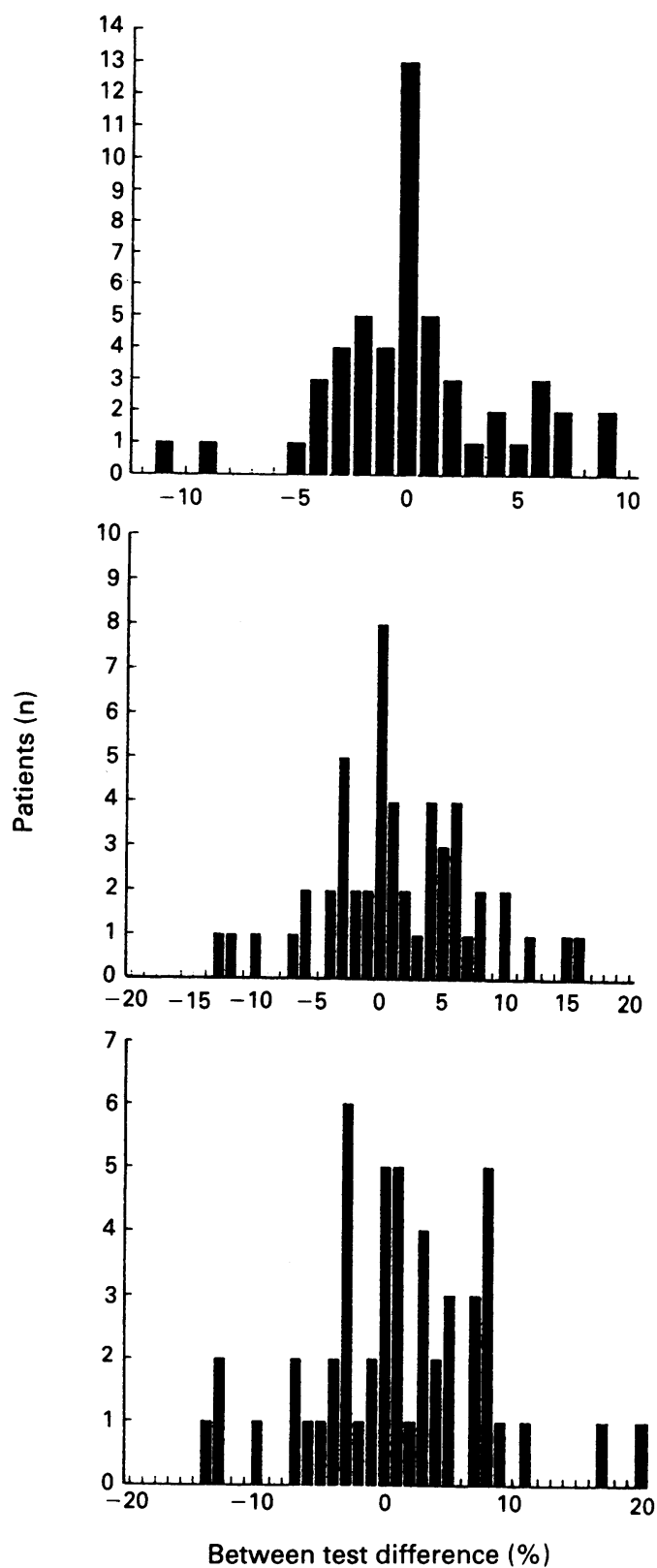

The regression line was not different from the line of unity ( $95 \%$ CI 0.91 to 1.09 ; fig 1 ). For actual baseline resting LVEF of $57 \%$, $55 \%, 50 \%, 45 \%, 40 \%, 35 \%$, and $30 \%$, the corresponding lower limit of the $95 \%$ prediction interval was $49 \%, 47 \%, 42 \%, 37 \%$, $32 \%, 27 \%$, and $22 \%$ (fig 1 ). Thus for resting LVEF, the $95 \%$ prediction intervals (\%) were equal to baseline values \pm 8 .

\section{EXERCISE LVEF}

There was no significant group variability in peak exercise LVEF (mean (SD) 1\% (6\%) $95 \%$ CI 0 to +3 , table 1 ). The subgroup ( =24) with normal baseline exercise LVEF $(\geqslant 50 \%)$ showed no significant between-test difference (mean 0\% (7\%); $95 \%$ CI -2 to $+3)$. The proportion of patients with $<10 \%$ absolute difference between baseline and sixmonth measurements was 46 of 51 (90\%, fig 3).

The regression line was not different from the line of unity ( $95 \%$ CI 0.88 to $1 \cdot 14$, fig 1 ).
For baseline exercise LVEF values of $60 \%$, $55 \%, 50 \%, 45 \%, 40 \%, 35 \%$ and $30 \%$, the respective lower limit of the $95 \%$, prediction interval was $49 \%, 44 \%, 38 \%, 33 \%, 28 \%$, $23 \%$, and $18 \%$ (fig 1). Thus for a given baseline value, the $95 \%$ prediction interval allowed for a fall of $\leqslant 12 \%$ over six months without necessarily indicating or missing true deterioration.

\section{$\triangle$ LVEF WITH EXERCISE}

There was no significant group variability in $\triangle \mathrm{LVEF}$ (mean (SD) $-1 \%(7 \%) ; 95 \% \mathrm{CI}$ -1 to +3 , table 1$)$. There was also no significant between-test difference (mean (SD) $1 \%,(7 \%) ; 95 \% \mathrm{CI}-2$ to +3$)$ in the 31 patients with a baseline exercise induced fall in LVEF of $\leqslant 5 \%$. The proportion of patients showing $<10 \%$ absolute between-test difference in $\triangle L V E F$ was 45 of 51 (88\%, fig 3).

The regression coefficient was 0.80 (95\% CI 0.62 to 0.98 , fig 1 ). When there was no change in LVEF with exercise, or a rise of $1 \%$ to $11 \%$, the lower limit of the $95 \%$ prediction interval allowed for a fall at six months ranging from $5 \%$ to $13 \%$ (fig 1 ).

APPARENT DETERIORATION DURING EXERCISE AT SIX MONTHS

For exercise LVEF and $\triangle \mathrm{LVEF}$, apparent deterioration was defined as an absolute decrease of $1 \%$ or more from the baseline value. At six months, 22 patients (mean age 58 , range $37-71 ; 20$ men), despite remaining stable and event free, showed apparent deterioration in exercise LVEF only $(\mathbf{n}=3)$, $\triangle$ LVEF only $(n=5)$, or both $(n=14$, table $2)$. For either of these prognostic indices, only two patients had six month values that were below the lower limit of the $95 \%$ prediction interval, compared with 15 patients if $95 \%$ CIs of the group were applied $(z=3.33$, $\mathrm{p}<0.001$ ).

Overall, all but three patients had sixmonth measurements that fitted within $95 \%$ prediction intervals (table 2). In patient $\mathrm{F}$, $\triangle \mathrm{LVEF}$ was $-13 \%$ at baseline and $-26 \%$ at six months; this deterioration was accompanied by the development of symptom free left bundle branch block. Subsequent arteriography undertaken as part of an acute drug trial showed no progression of her isolated left anterior descending stenosis. At six months, patient G's exercise LVEF had fallen from $83 \%$ at baseline to $70 \%$, but this was still well above the lower limit of normal. Finally, patient Q's six-month measurements of both indices were worse than predicted, but he remained stable over the ensuing nine months.

Over the entire study period of 15 months, none of the 51 patients had any adverse cardiac event or underwent repeat arteriography for new or worsening symptoms. There was no significant baseline difference between the patients with and those without "deterioration" with respect to mean age, resting LVEF, exercise LVEF, $\triangle \mathrm{LVEF}$, and the proportion taking $\beta$ blockers or with previous myocardial infarction or triple vessel disease. 
Table 2 Baseline, predicted, and actual values at six months in 22 patients showing apparent deterioration

\begin{tabular}{|c|c|c|c|c|c|c|}
\hline \multirow[b]{2}{*}{ Patient } & \multicolumn{3}{|c|}{ Exercise LVEF (\%) } & \multicolumn{3}{|c|}{$\triangle L V E F(\%)$} \\
\hline & Baseline & Predicted $(95 \%$ CI) & Actual $(95 \%$ PI) & Baseline & Predicted (95\% CI) & Actual $(95 \%$ PI) \\
\hline $\begin{array}{l}\text { A } \\
\text { B } \\
\text { C } \\
\text { D } \\
\text { E } \\
\text { F } \\
\text { G } \\
\text { H } \\
\text { I } \\
\text { J } \\
\text { L } \\
\text { L } \\
\text { M } \\
\text { N } \\
\text { O } \\
\text { P } \\
\text { Q } \\
\text { R } \\
\text { S } \\
T \\
\text { U } \\
\text { V }\end{array}$ & $\begin{array}{l}36 \\
56 \\
31 \\
43 \\
35 \\
48 \\
83 \\
30 \\
58 \\
49 \\
38 \\
52 \\
35 \\
70 \\
53 \\
48 \\
58 \\
44 \\
66 \\
73 \\
52 \\
53\end{array}$ & $\begin{array}{l}37(35 \text { to } 38) \\
57(55 \text { to } 59) \\
32(30 \text { to } 33) \\
44(42 \text { to } 45) \\
36(34 \text { to } 37) \\
49(47 \text { to } 51) \\
85(82 \text { to } 87) \\
31(30 \text { to } 32) \\
59(57 \text { to } 61) \\
50(48 \text { to } 52) \\
39(37 \text { to } 40) \\
53(51 \text { to } 55) \\
36(34 \text { to } 37) \\
71(69 \text { to } 74) \\
54(52 \text { to } 56) \\
49(47 \text { to } 51) \\
59(57 \text { to } 61) \\
45(43 \text { to } 46) \\
67(65 \text { to } 70) \\
74(72 \text { to } 77) \\
53(51 \text { to } 55) \\
54(52 \text { to } 56)\end{array}$ & $\begin{array}{l}40(24 \text { to } 49) \\
46(45 \text { to } 70) \\
29(19 \text { to } 44) \\
37(31 \text { to } 56) \\
36(23 \text { to } 48) \\
44(36 \text { to } 61) \\
70(72 \text { to } 97) \\
30(18 \text { to } 43) \\
55(47 \text { to } 72) \\
46(37 \text { to } 62) \\
35(26 \text { to } 51) \\
46(41 \text { to } 65) \\
28(23 \text { to } 48) \\
66(59 \text { to } 84) \\
59(42 \text { to } 66) \\
45(36 \text { to } 61) \\
46(47 \text { to } 72) \\
49(32 \text { to } 57) \\
65(55 \text { to } 80) \\
72(62 \text { to } 87) \\
50(41 \text { to } 65) \\
50(42 \text { to } 66)\end{array}$ & $\begin{array}{r}-2 \\
-2 \\
-4 \\
-12 \\
-7 \\
-13 \\
+24 \\
-10 \\
-2 \\
-10 \\
-6 \\
+2 \\
+13 \\
+13 \\
+7 \\
-7 \\
0 \\
-27 \\
+21 \\
+23 \\
+11 \\
-8\end{array}$ & $\begin{array}{l}-2(-2 \text { to }-1) \\
-2(-2 \text { to }-1) \\
-3(-4 \text { to }-2) \\
-10(-12 \text { to }-7) \\
-6(-7 \text { to }-4) \\
-10(-13 \text { to }-8) \\
+19(+15 \text { to }+23) \\
-8(-10 \text { to }-6) \\
-2(-2 \text { to }-1) \\
-8(-10 \text { to }-6) \\
-5(-6 \text { to }-4) \\
+2(+1 \text { to }+2) \\
+10(+8 \text { to }+13) \\
+10(+8 \text { to }+13) \\
+6(+4 \text { to }+7) \\
-6(-7 \text { to }-4) \\
0(0 \text { to } 0) \\
-21(-26 \text { to }-17) \\
+17(+13 \text { to }+20) \\
+18(+14 \text { to }+22) \\
+9(+7 \text { to }+11) \\
-6(-8 \text { to }-5)\end{array}$ & $\begin{array}{r}-4(-15 \text { to }+12) \\
-3(-15 \text { to }+12) \\
-7(-16 \text { to }+10) \\
-15(-23 \text { to }+4) \\
-13(-19 \text { to }+8) \\
-26(-24 \text { to }+3) \\
+11(+5 \text { to }+33) \\
-15(-21 \text { to }+5) \\
-1(-15 \text { to }+12) \\
-13(-21 \text { to }+5) \\
-9(-18 \text { to }+8) \\
-8(-12 \text { to }+15) \\
+6(-3 \text { to }+24) \\
+9(-3 \text { to }+24) \\
+4(-8 \text { to }+19) \\
-10(-19 \text { to }+8) \\
-14(-13 \text { to }+13) \\
-28(-36 \text { to }-7) \\
+17(+3 \text { to }+30) \\
+16(+4 \text { to }+32) \\
+12(-5 \text { to }+22) \\
0(-20 \text { to }+7)\end{array}$ \\
\hline
\end{tabular}

95\% PI, 95\% prediction interval.

\section{Discussion}

STUDY RATIONALE

The method of first pass radionuclide ventriculography is well suited to the study of the natural history of cardiac disease. ${ }^{10}$ For groups of patients with coronary disease, the short-term reproducibility of analysis of left ventricular function has been extensively reported, albeit limited to indices only at rest. $^{71112}$ Although biological variability may be minimised by repeating the test within a short time, short-term results may not be relevant to long-term serial evaluation. Similarly, group mean data may not apply to the assessment of individual patients.

Moreover, equilibrium studies in patients with ischaemic heart disease have not examined reproducibility beyond four to six weeks. ${ }^{13-15}$ Even this period does not reflect the more usual follow up practice of half yearly or annual retesting. Also, there are sparse data on the reproducibility of the method when systematically performed with anti-ischaemic medication. Finally, the problem of how to define long-term "deterioration" in prognostic LVEF indices in the individual patient has not been considered.

\section{PATIENT SELECTION}

This study has therefore focused on the longterm reproducibility of, and prediction intervals for, LVEF measurement in medically treated patients with minimally symptomatic non-critical coronary artery disease that could be revascularised. Such patients were selected for study because they constitute a sizable group who, having undergone arteriography, are initially recommended conservative management. In some cases, medical treatment may initially be advised to avoid premature revascularisation. ${ }^{16}$ In others, the decision between early revascularisation or continuing with medical treatment may be borderline. In all these patients, the purpose of follow up is to help decide on the optimal timing of potential intervention. Such continuing care may incorporate regular stress tests.

\section{PRACTICAL CONSIDERATIONS}

Although our study did not specifically test for an exercise training effect, we found that at six months, as many patients improved their LVEF indices as did not, and there was no change in heart rate at rest or exercise from baseline. Even if evident, a training effect would tend to lead to improvement in six-month results, a phenomenon that, although desirable is of far less clinical import than deterioration despite clinical stability on medication.

Patients may have minimal symptoms because they are already well established on medication. Stress tests without the need for temporarily stopping such medication avoids the anxiety that may sometimes accompany withdrawal from treatment. Furthermore, prognostic radionuclide ventriculography may be more helpful if performed with rather than without anti-ischaemic medication. ${ }^{17}$

PREDICTION INTERVALS

Assuming that deterioration from baseline may indicate the increased propensity to instability that serial tests aim to detect, what change in ejection fraction should be considered clinically important for the individual patient?

Some guidance may be derived from the $95 \%$ prediction intervals that specify the statistically ordered limits within which an individual patient's subsequent result should lie within $95 \%$ probability. A subsequent measurement outside the lower limit of $95 \%$ prediction intervals would indicate with $95 \%$ certainty a real change from baseline-that is, a true deterioration in the individual patient. Conversely, a result that remains well within the $95 \%$ prediction intervals remains within the random variation inherent in the test as applied to the individual patient. Thus on the basis of probability, the lower limit suggests the minimum change that might be considered clinically important.

In this study, prediction intervals were based on 51 patients who had remained 
stable and event free between baseline and six-month tests, and for up to nine months thereafter. Increasing the sample size does not significantly narrow prediction intervals because they mainly reflect the scatter of individual data about the fitted regression line. ${ }^{8}$ When trying to predict six-month values, these prediction intervals imply greater variability of measurement for an individual patient compared with narrower CIs for a group of patients. For example, for a baseline exercise LVEF of $50 \%$, the six month measurement (assuming no real change) would be expected to lie between $49 \%$ and $53 \%$ $(95 \% \mathrm{CI})$ in a group, and in the individual patient, between $38 \%$ and $63 \%$ (95\% prediction interval).

\section{STUDY LIMITATIONS}

As the antithesis of reproducibility, unpredictability is not only inherent in behaviour of coronary disease but also it may be largely independent of anatomical progression. It has been assumed, however, that any progression that is significant enough may be reflected in deterioration of the ejection fraction response to exercise. Because this clinical study was not designed to detect subclinical progression of coronary artery disease, arteriography was repeated only if clinically indicated. Performed just once, arteriography poorly predicts the time and location of subsequent myocardial infarction, ${ }^{18-20}$ but when progression can be shown on serial tests, it may reflect potentially aggressive disease. ${ }^{21}$ Progression of the coronary lesions themselves occurs unpredictably, ${ }^{22} 23$ and the minimum change required for defining true progression is set arbitrarily. ${ }^{2024}$ There is thus no perfect test-whether anatomical or functional-to predict an imminent adverse cardiac event. Furthermore, a few patients may show excessive between-test variability with radionuclide ventriculography, thereby precluding their benefit from further tests.

\section{CLINICAL PERSPECTIVE}

These limitations should not detract from the purpose of follow up for most patients, which is to detect simply, reliably, and non-invasively a clinically significant change from baseline so that appropriate and timely intervention can be considered. Whether prediction intervals should be tightened (set at a probability lower than $95 \%$, such as $90 \%$ ) can only be determined when further study incorporates systematic quantitative coronary arteriography to test subclinical progression to critical anatomical disease and the criteria for prognostically significant results are defined for radionuclide ventriculography performed with medication. For the present, the clinical importance of a result that approaches or exceeds the lower limit specified by prediction intervals depends on the clinician being alerted to review the need for repeat arteriography or timely revascularisation in the patients. Such a strategy may find potential application in other clinical situations where the interpretation of serial changes relates to the individual patient rather than to a group.

\section{CONCLUSION}

Applying a design that reflects routine clinical practice in a well characterised commonly encountered population, this study has shown that the long-term serial measurement of prognostic LVEF indices is sufficiently predictable to contribute to the follow up of the individual patient with coronary artery disease. In the minimally symptomatic patient who is initially treated medically, serial changes in these prognostic indices may be interpreted more meaningfully with reference to $95 \%$ prediction intervals, either indicating stability or alerting the clinician to the need for closer review.

This study was supported by a project grant from the St Bartholomew's Hospital Joint Research Board.

1 Pryor DB, Harrell FE Jr, Lee KL, Rosati RA, Coleman $\mathrm{RE}$, Cobb FR, et al. Prognostic indicators from radionuclide angiography in medically treated patients with coronary artery disease. Am $\mathcal{F}$ Cardiol 1984;53:18-22.

2 Lee KL, Pryor DB, Pieper KS, Harrell FE Jr, Califf RM, Mark DB, et al. Prognostic value of radionuclide angiography in medically treated patients with coronary artery disease. A comparison with clinical and catheteriartery disease. A comparison with clinical and

3 Jones RH, Floyd RD, Austin EH, Sabiston DC Jr. The role of radionuclide angiocardiography in the preoperative prediction of pain relief and prolonged survival following coronary artery bypass grafting. Ann Surg 1983;197:743-54.

4 Bonow RO, Kent KM, Rosing DR, Lan KKG, Lakatos E, Borer JS, et al. Exercise-induced ischemia in mildly symptomatic patients with coronary-artery disease and preserved left ventricular function. Identification of subgroups at risk of death during medical therapy. $N$ Engl $\mathcal{F}$ Med 1984;311:1339-45.

$5 \mathrm{Lim}$ R, Dymond DS. Prognostic assessment of coronary artery disease by exercise radionuclide ventriculography. In: Reiber JHC, van der Wall EE, eds. Cardiovascular nuclear medicine and MRI. Quantitation and clinical applications. Dordrecht: Kluwer Academic Publishers, 1992: cations.

6 Dymond DS. Standards for acquisition, data analysis and interpretation of myocardial scintigraphy and blood pool scintigraphy. In: Simoons ML, Reiber JHC, eds. Nuclear imaging in clinical cardiology. Boston: Martinus Nijhoff, 1984:233-52.

7 Dymond DS, Elliott A, Stone D, Hendrix G, Spurrell R. Factors that affect the reproducibility of measurements of left ventricular function from first-pass radionuclide ventriculograms. Circulation 1982;65:311-22.

8 Altman DG. Practical statistics for medical research. London: Chapman and Hall, 1991:306-15.

9 Bland JM, Altman DG. Statistical methods for assessing agreement between two methods of clinical measurement. Lancet 1986;i:307-10.

10 Dymond DS. Radionuclide assessment of ventricular function in patients with coronary artery disease: clinical function in patients with coronary artery dise

11 Marshall RC, Berger HJ, Reduto LA, Gottschalk A, Zaret BL. Variability in sequential measures of left ventricular performance assessed with radionuclide angiocardiography. Am f Cardiol 1978;41:531-6.

12 Dymond DS, Elliott AT, Flatman W, Stone D, Bett R Cuninghame $G$, et al. The clinical validation of Gold195m: A new short half-life radiopharmaceutical for rapid, sequential, first pass angiocardiography in patients. F Am Coll Cardiol 1983;2:85-92.

13 Wackers FJT, Berger HJ, Johnstone DE, Goldman L Reduto LA, Langou RA, et al. Multiple gated cardiac blood pool imaging for left ventricular ejection fraction: validation of the technique and assessment of variability. Am $\mathcal{F}$ Cardiol 1979;43:1159-65.

14 Hoilund-Carlsen PF, Lauritzen SL, Marving J, Rasmussen S, Hesse B, Folke K, et al. The reliability of measuring left ventricular ejection fraction by radionuclide cardiography: evaluation by the method of variclide cardiography: evaluation by the method
ance components. Br Heart $\mathcal{F}$ 1988;59:653-62.

15 Mahmarian JJ, Moye L, Verani MS, Eaton T, Francis M, Pratt CM. Criteria for the accurate interpretation of changes in left ventricular ejection fraction and cardiac volumes as assessed by rest and exercise gated radionuvolumes as assessed by rest and exercise gated radion

16 Kirklin JW, Frye RL, Blackstone EH, Naftel DC. Some comments on the indications for the coronary artery bypass graft operation. Int $\mathcal{f}$ Cardiol 1991;31:23-30.

$17 \mathrm{Lim}$ R, Dymond DS. Should antianginal medication be stopped for exercise testing? Lancet 1992;340:161-2. 
18 Little WC, Constantinescu M, Applegate RJ, Kutcher MA, Burrows MT, Kahl FR, et al. Can coronary angiography predict the site of a subsequent myocardial infarction in patients with mild-to-moderate coronary artery disease? Circulation 1988;78:1157-66.

19 Ambrose JA, Tannenbaum MA, Alexopoulos D, Hjemdahl-Monsen CE, Leavy J, Weiss $M$, et al. Angiographic progression of coronary artery disease and the development of myocardial infarction. $7 \mathrm{Am}$ Coll Cardiol 1988;12:56-62.

20 Lichtlen PR, Nikutta P, Jost S, Deckers J, Wiese B, Rafflenbeul W, and the INTACT Study Group Anatomical progression of coronary artery disease in humans as seen by prospective, repeated, quantitated coronary angiography: relation to clinical events and risk factors. Circulation 1992;86:828-38.

21 Moise A, Bourassa MG, Theroux P, Taeymans Y,

\section{Appendix}

For a given baseline measurement $\mathrm{x}_{0}$, the estimated standard deviation $\left(\mathrm{SD}_{\mathrm{e}}\right)$ of individual predicted 6-month values is given by

$$
\mathrm{SD}_{\mathrm{e}}=\mathrm{SD}_{\mathrm{res}} \sqrt{1+1 / n+\left(x_{0}-\bar{x}\right)^{2} / \mathrm{S}_{x x}}
$$

where $n=$ sample size

$$
\begin{aligned}
\bar{x} & =\text { mean of } X \text { values } \\
S_{x x} & =\Sigma \bar{x}_{i}^{2}\left(\Sigma x_{i}\right)^{2 / n}
\end{aligned}
$$

that is, the sum of squares of $X$ values about their means.

The residual standard deviation $\left(\mathrm{SD}_{\mathrm{res}}\right)$ is a measure of the goodness-of-fit of the regression line in the units of measurement,
Pasternac A, Campeau L, et al. Prognostic significance of progression of coronary artery disease. Am $₹$ Cardiol 1985;55:941-6.

22 Davies MJ, Thomas AC. Plaque fissuring - the cause of acute myocardial infaraction, sudden ischaemic death, and crescendo angina. Br Heart $f$ 1985;53:363-73.

23 Bruschke AVG, Kramer JR Jr, Ba ET, Haque IU, Detrano RC, Goormastic M. The dynamics of progresDetrano RC, Goormastic $M$. The dynamics of progresically treated patients who underwent coronary arteriography three times. Am Heart $f$ 1989;117: arteriography

24 Reiber JHC, Serruys PW, Kooijman CJ, Wijns W, Slager JJ, Gerbrands JJ, et al. Assessment of short-, medium-, and long-term variations in arterial dimensions from computer-assisted quantitation of coronary cineangiograms. Circulation 1985;71:280-8.

and is given by

$$
\begin{aligned}
& \mathrm{S}_{\mathrm{res}}=\sqrt{1 / n-2\left(\mathrm{~S}_{\mathrm{yy}}-b \mathrm{~S}_{x y}\right)} \\
& \mathrm{S}_{y y}=\Sigma y_{i}^{2}-\left(\Sigma y_{i}\right)^{2} / n
\end{aligned}
$$

that is, the sum of squares of $\mathrm{Y}$ values about their means.

$$
\mathrm{S}_{x y}=\sum x_{i} y_{i}-\left(\sum x_{i} \sum y_{i}\right) / n
$$

that is, the sum of products.

$$
b=\text { slope of regression line. }
$$

Thus for a given baseline measurement the 95\% prediction interval for a predicted 6month value

$=$ Predicted 6-month value $\pm\left(\mathrm{t}_{0.975}-\mathrm{SD}_{\mathrm{e}}\right)$ where $t$ is on $n-2$ degrees of freedom. 
The host hospital should have:

(a) A cardiac arrest team trained in cardiopulmonary resuscitation

(b) A cardiac care unit with facilities for temporary pacing

(c) A volume of work sufficient to maintain expertise. Levels agreed in the document "Strategic planning for cardiac services and the internal market: role of catheterisation laboratories in district general hospitals" seem appropriate for individual operators

(d) Links with a specialist/surgical centre for urgent transfer of patients if needed.

The host hospitals should ensure:

(a) That their radiological protection officer, infection control officer, and fire prevention officer all are satisfied about arrangements both for routine operating and in case of emergency

(b) That the mobile catheter laboratory is linked directly to the host hospital switchboard

(c) That all the potential members of the host hospital's cardiac arrest team (physicians, anaesthetists, and porters) are aware of the location of the mobile laboratory and how to gain access when required in an emergency

(d) That appropriate arrangements are made for patients to go between the mobile catheter laboratory and an area for recovery staffed by nurses who have had specific training in the care of arterial puncture sites and complications of catheterisation. This area should have full resuscitation equipment

(e) That all personnel directly involved in patient care have read any procedure manual agreed between the parties

(f) That all patients using the mobile catheter laboratory have adequate registration data and case records and that all records of the procedure (film, video, pressure data) are archived at an agreed site

(g) That the manager of the mobile catheter laboratory is given 36 hours' warning if any of the patients is infected with HIV or hepatitis B or presents any other infection risk

(h) That if patients are catheterised in a district general hospital the consultant cardiologist is on site and immediately available

(i) That if patients are catheterised in the mobile laboratory by a visiting cardiologist, the local physician who has responsibility for the patients is clearly defined and that he/she is suitably trained to manage complications of catheterisation after the visiting cardiologist has left the site.
The manager of the mobile catheter laboratory is responsible for:

(a) Ensuring that the parties agree procedures and responsibilities before clinical work begins

(b) Ensuring the smooth operating of the equipment and that all safety standards are met

(c) That all staff provided by the mobile catheter laboratory company are adequately trained for their roles

(d) That full and functioning resuscitation equipment is carried on the mobile catheter laboratories and that staff are proficient in cardiopulmonary resuscitation.

\section{APPROPRIATE PROCEDURES}

Where a mobile laboratory is used in a hospital that also has a fixed catheterisation laboratory all catheterisation procedures including coronary angioplasty can be undertaken.

If the mobile laboratory is visiting a hospital that does not have a fixed laboratory only diagnostic catheterisation should be undertaken. Angioplasty is not appropriate because if there is a vessel occlusion after the mobile laboratory has left the premises there will be no facilities available for imaging. Patients likely to require urgent intervention should be referred to a tertiary centre.

Provided that these guidelines are adhered to there is no reason to suppose that safety standards will be any different in mobile laboratories and fixed laboratories. We recommend, however, that the UK Confidential Enquiry into Cardiac Catheter Complications develop a means of identifying cases catheterised in mobile laboratories to enable appropriate audit so that complication rates can be compared with those of fixed laboratories. Both NHS and private laboratories should return data.

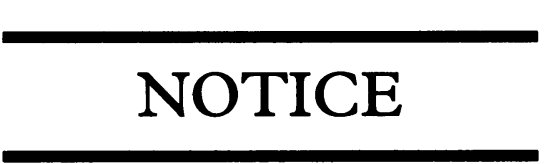

The 1994 Annual Meeting of the British Cardiac Society will take place at the Riviera Centre, Torquay from 17 to 20 May.

\section{CORRECTION}

Novel approach to the interpretation of long-term "deterioration" in ejection fraction in individual patients with coronary artery disease. Richard Lim, Lorraine Dyke, fanice Thomas, Duncan $S$ Dymond

Several errors appeared in the appendix to this article ( $\mathrm{Br}$ Heart $\mathcal{f} 1993 ; 70: 226-32)$. A corrected version appears below.

Appendix

For a given baseline measurement $x_{0}$, the estimated standard deviation $\left(\mathrm{SD}_{e}\right)$ of individual predicted 6 -month values is given by

$$
\mathrm{SD}_{\mathrm{e}}=\mathrm{SD}_{\mathrm{res}} \sqrt{1+(1 / n)+\left\{\left(x_{0}-\bar{x}\right)^{2} / \mathrm{S}_{x x}\right\}}
$$

where $n=$ sample size

$$
\begin{aligned}
& \bar{x}=\text { mean of } X \text { values } \\
& \mathrm{S}_{x x}=\Sigma x_{i}^{2}-\left\{\left(\Sigma x_{i}\right)^{2} / n\right\}
\end{aligned}
$$

that is, the sum of squares of $X$ values about their mean.

The residual standard deviation $\left(\mathrm{SD}_{\mathrm{rea}}\right)$ is a measure of the goodness-of-fit of the regression line in the units of measurement, and is given by

$$
\mathrm{SD}_{\mathrm{res}}=\sqrt{\left(\mathrm{S}_{\mathrm{yy}}-b \mathrm{~S}_{\mathrm{xy}}\right) /(n-2)}
$$

where $S_{y y}=\Sigma y_{i}^{2}-\left\{\left(\Sigma y_{i}\right)^{2} / n\right\}$

that is, the sum of square of $\mathrm{Y}$ values about their mean.

$$
\mathrm{S}_{\mathrm{xy}}=\Sigma x_{i} y_{i}-\left\{\left(\Sigma x_{i} \Sigma y_{i}\right) / n\right\}
$$

that is, the sum of products.

$b=$ slope of regression line.

Thus for a given baseline measurement the $95 \%$ prediction interval for a predicted 6-month value

$=$ Predicted 6 -month value $\pm\left(t_{0.975} \times \mathrm{SD}_{\mathrm{e}}\right)$ where $t$ is on $n-2$ degrees of freedom. 